\title{
Association of 2-hour Plasma Glucose (2H-PG) with Lipid Profile in Selected Diabetic Families from Hyderabad Sindh Pakistan
}

\author{
Latafat Ali Chughtai, Jawaid Ahmed Zai, Zaib u Nisa Mughal, Benazir Faheem
}

\section{ABSTRACT}

OBJECTIVE: To determine the association of 2-hour plasma glucose ( $2 \mathrm{~h}-\mathrm{PG}$ ) duration with lipid profile in families suffering from diabetes mellitus type-2with impaired lipid metabolism.

METHODOLOGY: A cross sectional experimental study was conducted for the duration of thirteen months. Sample size was $274(n=274)$, Subjects with predisposed background of Type 2 diabetes were evaluated for the relationship between hyperglycemia and lipid profile, for this blood samples from father, mother and siblings were taken. The data is presented according to 2-hour plasma glucose in blood.

RESULTS: The persons those are suffering from diabetes type-2 show the mean values of $2 \mathrm{H}-\mathrm{PG}=$ 250.17, $S D=26.81$. Total cholesterol $=236.50, S D=19.35$, correlation coefficient $=0.81$, $P$ : 2-tailed $=0.00$. $\mathrm{HDL}=47.03, \mathrm{SD}=4.33$, correlation coefficient $=-0.21, \mathrm{P}: 2$-tailed $=0.00$; $L D=179.04, \mathrm{SD}=21.96$, correlation coefficient $=0.73$, P: 2-tailed $=0.00 ; \mathrm{VLDL}=39.84, \mathrm{~S} . \mathrm{D}=6.62$, correlation coefficient $=-0.10$, P: 2-tailed $=0.00$; Total Cholesterol I $\mathrm{HDL}=5.08$ S.D $=0.73$, correlation coefficient $=0.62$, P: 2-tailed $=0.00$; Triglycerides $=184.99, S D=25.35$, correlation coefficient $=0.78, P: 2$-tailed $=0.00$; $F P G=193.28$, $S D=20.14$, correlation coefficient $=0.06$, $P$ : 2-tailed $=0.00, \mathrm{HbA1C}=6.81$, $\mathrm{SD}=0.71$, correlation coefficient $=0.29, \mathrm{P}$ : 2-tailed $=0.00, B M I=25.54, S D=2.06$, correlation coefficient $=0.37, P:$ 2-tailed $=0.00$.

CONCLUSION: We concluded that diabetic patients have the high risk of developing various diseases including CVD, therefore in order to prevent from more complications observance of lipid guidelines is very important for improvement of disease.

KEY WORDS: Lipid profile, 2 Hour plasma Glucose (2H-PG), Diabetes

This article may be cited as: Chughtai LA, Zai JA, Mughal ZN, Faheem B. Association of 2-hour Plasma Glucose (2H-PG) with Lipid Profile in Selected Diabetic Families from Hyderabad Sindh Pakistan. J Liaquat Uni Med Health Sci. 2018;17(04):215-20. doi: 10.22442/jlumhs. 181740580

\section{INTRODUCTION}

Multiple factors have been reported of the association diabetes mellitus with lipid profile. Type 2 diabetes is diagnosed when the cells stop responding to insulin often due to insulin resistance ${ }^{1}$, and the pancreas try to compensate it by producing more and more insulin to maintain normal blood sugar levels ${ }^{2}$. The fasting blood sugar level $\geq 7.0 \mathrm{mmol} / \mathrm{l}(126 \mathrm{mg} / \mathrm{dl})$ or $2-\mathrm{h}$ plasma glucose $\geq 11.1 \mathrm{mmol} / \mathrm{l}(200 \mathrm{mg} / \mathrm{dl})$ is used as model to detect diabetic families ${ }^{3}$. The persistent level of hyperglycemia gives rise to risk of micro vascular diseases such as retinopathy, in adults as well as premature babies ${ }^{4}$ neuropathy and nephropathy ${ }^{5,6}$. It also leads to the damage of macro vascular problems like coronary heart disease, heart stroke and peripheral vessels disease hence could lead to reduced quality of life ${ }^{7}$.

The world over estimates show that there were 171 million people with diabetes type-2 in the year 2000 and this is going to increase up to 366 million by the year $2030^{8}$. Diabetes type-2 is now being increasingly diagnosed in young population and even inchildren ${ }^{9}$.
In 1990, 4.9\% were diagnosed with diabetes in American population and this has increased to $7.9 \%$ by the year $2001^{10}$. Diabetes is considered as one of the most common metabolic disorders in the whole world and the frequency of diabetes in adults has been greatly increased in last few decades ${ }^{11}$.

The children of Japan suffer more from diabetes type-2 than type-1. The frequency of diabetes type-2 in childhood is approximately 3.0 per 100,000 and this disease seems to shift from diabetes type-I to diabetes type- 2 with advancing age ${ }^{12}$.

Studies on several populations indicate that loss of insulin secretion results in type-2 diabetes mellitus ${ }^{13}$. It is also proved that environmental factors may interact with the genes to produce the disorder ${ }^{10}$.

The most important risk factor for diabetes type-2 is obesity and sedentary life style that is also associated with high lipid profile and increased triglycerides level, decreased HDL and high LDL cholesterol levels ${ }^{14}$. Around $60-70 \%$ of the total cholesterol in the blood is in form of LDL, and VLDL makes up 10-15\%, whereas about $30 \%$ is in form of HDL blood 
cholesterol. The level of HDL is negatively correlated with the possibility of coronary heart diseas ${ }^{15,16}$.

\section{METHODOLOGY}

This Cross sectional / Experimental study was conducted from Jan 2015 to Jan 2016. Data was collected from the different areas of Hyderabad / Jamshoro.

Total Fifty families were selected for this study, sample size was 274 , participants were categorized into three categories that are Diabetic, Control and pre -diabetics. Among them, the families having clear pedigree of diabetes were selected. The other members with disturbed lipid profile who were not yet diagnosed as diabetics (borderline) were also selected. The families were visited at their place of residence and a detailed history was taken from the head of each family according to standard method.

The selection was based on the 2h-PG status. All the subjects were between the ages of 22 to 65 years of age. The control group comprised of 100 people, affected (diabetes type-2) group 90 and borderline 84 . Blood samples required for the study were collected from non-diabetics as normal controls and diabetic individuals of each family including their parents according to the procedure laid down by WHO.

Blood samples of $4 \mathrm{cc}$ collected through venipuncture from median cubital vein in5 $\mathrm{ml}$ syringes and then were immediately transferred into gel tubes for serum separation. The centrifugation of serum was carried out at $3000 \mathrm{rpm}$ for 10 minutes. Body mass index (BMI) was calculated from height and weight using the formula: BMI $=\left[\right.$ body weight (pounds)/height (inches) $\left.{ }^{2}\right]$ $\times$ 704.5. All the subjects were told to fast overnight. Fasting plasma concentrations of glucose, glycated hemoglobin $(\mathrm{HbA} 1 \mathrm{c})$ concentrations, lipid profile was quantified with Auto Analyzer-300 (Merck).

Data acquired were analyzed statistically by using SPSS Ver.21, data is provided as mean, and standard deviation, where " $n$ " represents the number of participants, variables are presented in the form of table and graphs.

\section{RESULTS}

The mean and standard deviation of $2 \mathrm{~h}-\mathrm{HG}$, lipid profile, fasting plasma glucose, $\mathrm{HbA} 1 \mathrm{C} \& \mathrm{BMI}$ (normal male \& female) is compared with the borderline and diabetics families' male \& female, clearly indicate that the $2 \mathrm{~h}-\mathrm{PG}$ in diabetic families having diabetes or at borderline have increased values as well as lipid profile, $\mathrm{HbA} 1 \mathrm{C}$ and $\mathrm{BMI}$ (Table I \& II).

The combined data of male \& female is presented in table-I also clearly indicate the same pattern. The data of lipid profile on gender basis is compared with 2-hour plasma glucose (2h-PG) in control, borderline and Diabetes type-2 families.

Correlation of $2 \mathrm{~h}-\mathrm{PG}$ with lipid profile is not significant in control group except for total cholesterol, HDL \& VLDL where slight positive results are seen (Table II). Significant correlation with $2 \mathrm{~h}-\mathrm{PG}$ is observed in case of Male gender diabetic group with all the parameters except HDL, VLDL and FPG similarly in case of diabetic female considerable correlation is observed except VLDL and fasting plasma glucose.(Table-III) The combined data of group of diabetic families show positive significance with all the parameters except

Table I: Mean and St. Dev. Values of $2 \mathrm{~h}-\mathrm{PG}$, lipid profile, HbA1C and BMI of control, borderline and Type 2 diabetes subjects (Male \& Female)

\begin{tabular}{|c|c|c|c|c|c|c|}
\hline \multirow[b]{2}{*}{ Parameter } & \multicolumn{2}{|c|}{ Control $(n=100)$} & \multicolumn{2}{|c|}{ Borderline $(n=84)$} & \multicolumn{2}{|c|}{ Diabetes type-II families $(n=90)$} \\
\hline & $\begin{array}{l}\text { Male }(n=60) \\
\text { Mean+SD }\end{array}$ & $\begin{array}{c}\text { Female }(n=40) \\
\text { Mean+SD }\end{array}$ & $\begin{array}{l}\text { Male }(n=42) \\
\text { Mean+SD }\end{array}$ & $\begin{array}{c}\text { Female }(n=42) \\
\text { Mean+SD }\end{array}$ & $\begin{array}{l}\text { Male }(n=54) \\
\text { Mean+SD }\end{array}$ & $\begin{array}{c}\text { Female } \\
(n=36) \\
\text { Mean+SD }\end{array}$ \\
\hline $\begin{array}{l}\text { 2-Hour Plasma Glucose } \\
\text { (mg/dl) }\end{array}$ & $110.36 \pm 12.06$ & $103.21 \pm 15.94$ & $163.13 \pm 12.56$ & $159.32 \pm 15.59$ & $252.80 \pm 26.74$ & $246.21 \pm 26.78$ \\
\hline Total Cholesterol (mg/dl) & $166.53 \pm 15.60$ & $157.03+21.62$ & $189.24+16.03$ & $177.98+19.99$ & $240.39+20.30$ & $230.67 \pm 16.43$ \\
\hline $\mathrm{HDL}(\mathrm{mg} / \mathrm{dl})$ & $39.88+5.42$ & $40.18 \pm 6.37$ & $49.04+7.48$ & $43.83+4.48$ & $47.32 \pm 3.56$ & $46.02 \pm 5.19$ \\
\hline $\operatorname{LDL}(\mathrm{mg} / \mathrm{dl})$ & $108.13 \pm 12.15$ & $101.66 \pm 12.86$ & $132.04+10.86$ & $124.50 \pm 12.07$ & $180.22+21.57$ & $174.69+22.48$ \\
\hline VLDL (mg/dl) & $18.12 \pm 8.42$ & $15.42+4.56$ & $35.29 \pm 3.10$ & $31.57 \pm 5.47$ & $41.04 \pm 6.52$ & $38.06 \pm 6.45$ \\
\hline Tot.chol/HDL ratio $(\mathrm{mg} / \mathrm{dl})$ & $4.24 \pm 0.61$ & $3.98 \pm 0.69$ & $3.94 \pm 0.62$ & $4.09 \pm 0.52$ & $5.12 \pm 0.71$ & $5.09+0.78$ \\
\hline Triglycerides (mg/dl) & $103.25+31.38$ & $95.99+32.18$ & $149.44+22.63$ & $145.15+17.89$ & $188.91+25.32$ & $179.10 \pm 24.57$ \\
\hline F.P. G (mg/dl) & $101.39+12.28$ & $96.27 \pm 13.99$ & $110.12 \pm 12.24$ & $103.05 \pm 6.68$ & $197.93+20.05$ & $186.31 \pm 18.41$ \\
\hline $\mathrm{HbA} 1 \mathrm{C}(\%)$ & $5.20 \pm 0.48$ & $4.91 \pm 0.56$ & $6.00 \pm 0.63$ & $5.80 \pm 0.51$ & $7.04 \pm 0.64$ & $6.47 \pm 0.69$ \\
\hline $\mathrm{BMI}$ & $20.83 \pm 1.67$ & $19.74 \pm 1.37$ & $23.09+2.07$ & $20.39 \pm 1.92$ & $27.64 \pm 3.64$ & $26.05+1.68$ \\
\hline
\end{tabular}


Latafat Ali Chughtai, Jawaid Ahmed Zai, Zaib u Nisa Mughal, Benazir Faheem

Table II: Mean and St. Dev. Values of $2 \mathrm{~h}-\mathrm{PG}$, lipid profile, HbA1C and BMI of control, borderline and Type 2 diabetes subjects (Male \& Female combined data)

\begin{tabular}{|c|c|c|c|}
\hline Parameter & Control $(n=100)$ & Borderline $(n=84)$ & Diabetes type-II families $(n=90)$ \\
\hline $\begin{array}{l}\text { 2-Hour Plasma Glucose (2h-PG) } \\
\text { (mg/dl) }\end{array}$ & $106.79 \pm 14.52$ & $163.17 \pm 14.20$ & $250.17 \pm 26.81$ \\
\hline Total Cholesterol(mg/dl) & $161.78 \pm 19.37$ & $185.82 \pm 18.88$ & $236.50 \pm 19.35$ \\
\hline $\mathrm{HDL}(\mathrm{mg} / \mathrm{dl})$ & $40.03 \pm 5.89$ & $46.99 \pm 6.66$ & $47.03 \pm 4.33$ \\
\hline $\mathrm{LDL}(\mathrm{mg} / \mathrm{dl})$ & $104.09 \pm 12.87$ & $129.82 \pm 12.02$ & $179.04 \pm 21.96$ \\
\hline $\operatorname{VLDL}(\mathrm{mg} / \mathrm{dl})$ & $16.77 \pm 8.46$ & $33.83+4.80$ & $39.84 \pm 6.62$ \\
\hline Tot.chol/HDL ratio (mg/dl) & $4.11 \pm 0.66$ & $4.06 \pm 0.58$ & $5.08 \pm 0.73$ \\
\hline Triglycerides(mg/dl) & $99.62 \pm 31.86$ & $149.07 \pm 20.39$ & $184.99 \pm 25.35$ \\
\hline $\begin{array}{l}\text { Fasting Plasma Glucose (FPG) } \\
(\mathrm{mg} / \mathrm{dl})\end{array}$ & $99.83 \pm 13.36$ & $107.87 \pm 10.42$ & $193.28+20.14$ \\
\hline $\mathrm{HbA} 1 \mathrm{C}(\%)$ & $5.05 \pm 0.54$ & $5.97 \pm 0.58$ & $6.81 \pm 0.71$ \\
\hline BMI & $20.29 \pm 1.62$ & $22+2.40$ & $27.01 \pm 3.10$ \\
\hline
\end{tabular}

Table III: Correlation of $2 \mathrm{~h}-\mathrm{PG}$ with control, borderline and Type 2 diabetes subjects (Male \& Female)

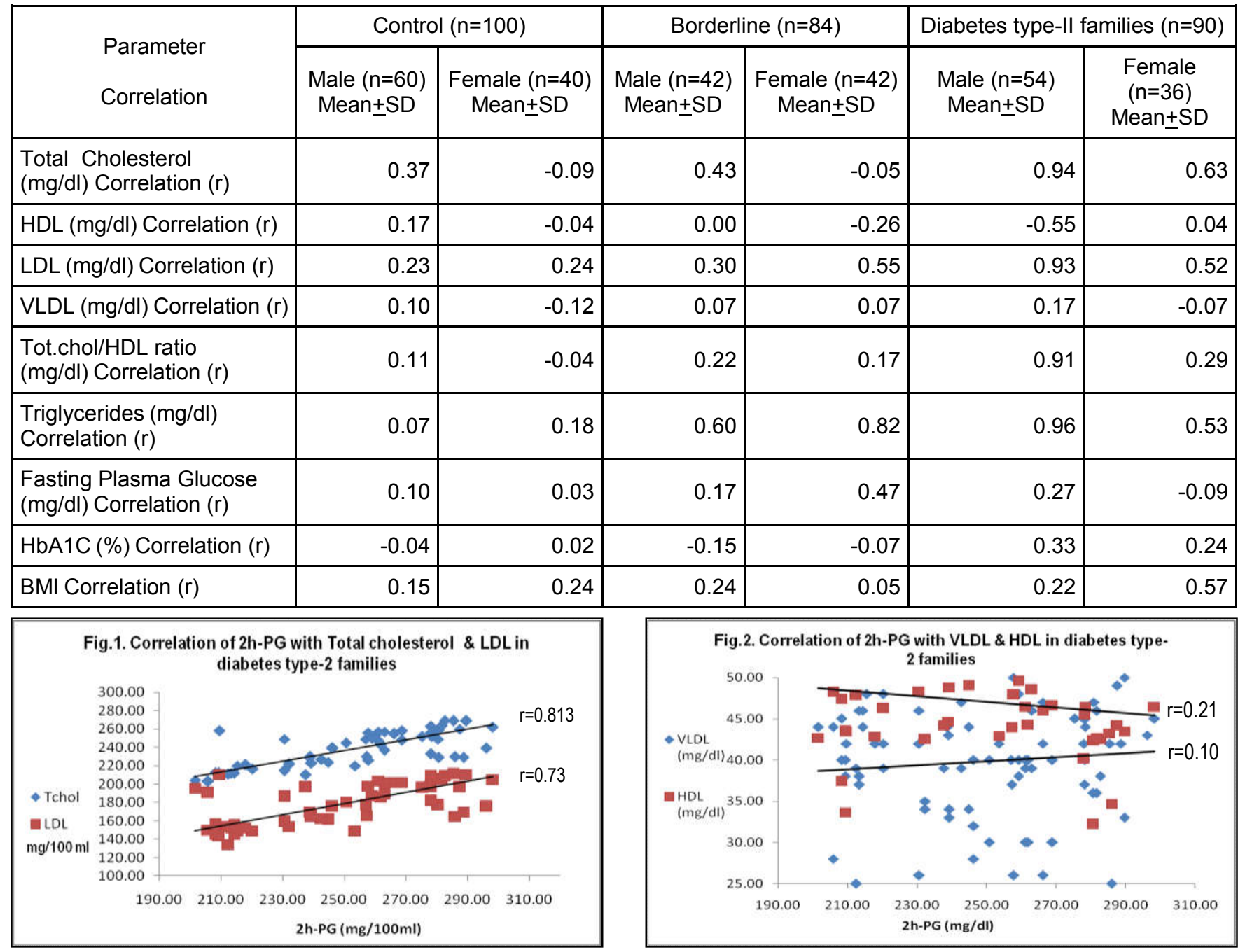


Association of 2-hour Plasma Glucose (2H-PG)

Table IV: Correlation of $\mathbf{2 h - P G}$ with control, borderline and Type 2 diabetes subjects (Combined data)

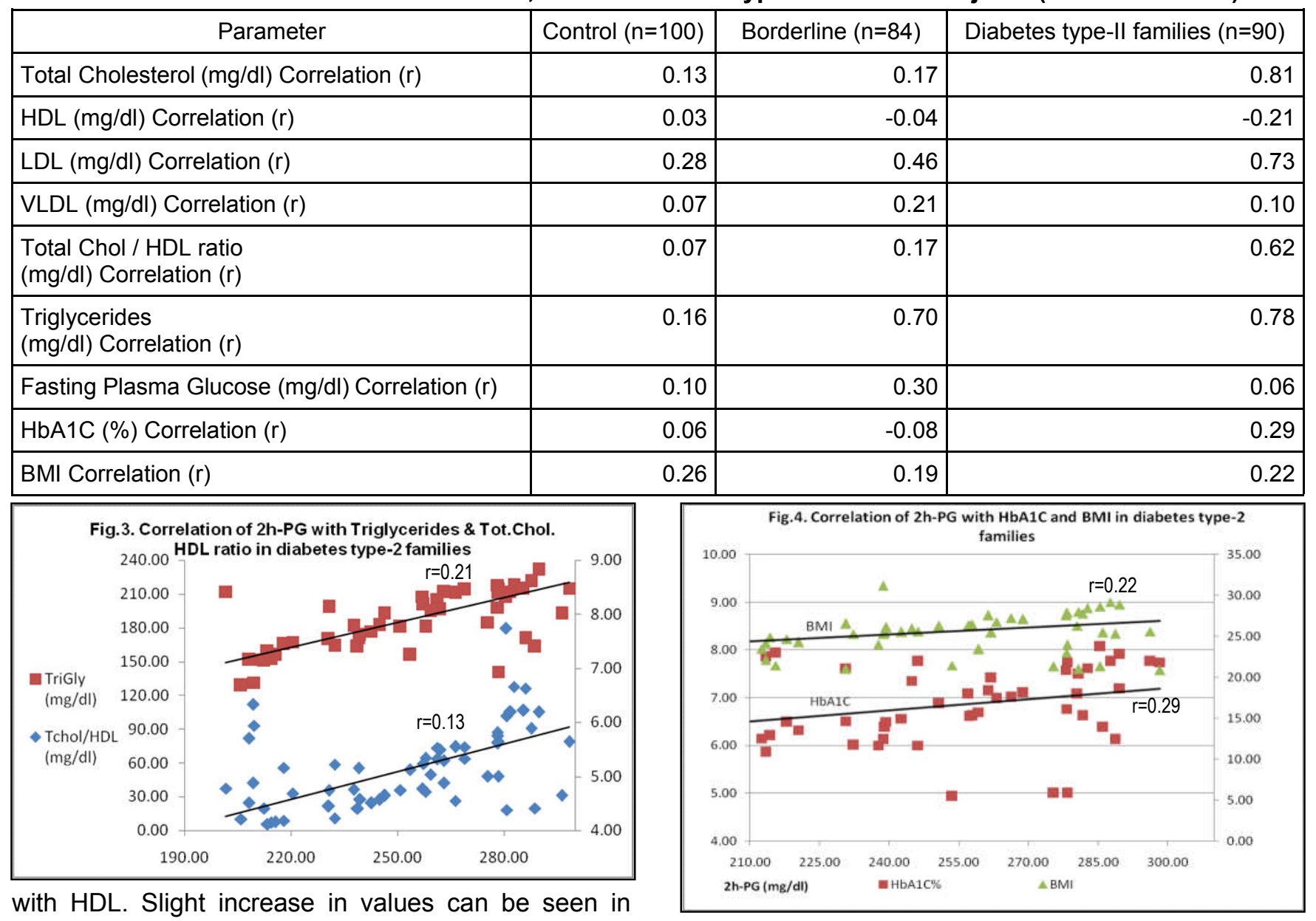

males of borderline group with cholesterol, LDL, VLDL, Cholestrol / HDL ratio, triglycerides, and BMI (Table IV, Fig.1-4).

\section{DISCUSSION}

The slight correlation is observed in case of male control with total cholesterol and LDL. In case of borderline male group slight correlation of $2 h-P G$ is observed with total cholesterol, LDL, VLDL, total Cholestrol/HDL ratio, triglycerides, while in case of female borderline group is have positive correlation with LDL, triglycerides and slightly with FPG because these belong the families where there is clear heredity of diabetes and were hyperglycemic, but yet they were not diagnosed with diabetes. The negative correlation is observed in $\mathrm{HbA} 1 \mathrm{C}$.

The reason that LDL \& VLDL are increased in borderline and in diabetes type-2 is because of altered metabolism ${ }^{9,17}$. The reason being HDL is negatively correlated because HDL tends to increase in normal subjects while it decreases with increase in lipid profile $^{18}$. The insulin can lead to a decrease of an enzyme called lipoprotein lipase. The lipoprotein

lipase enzyme breaks up the triglycerides in very low-density lipoprotein cholesterol so they can store inside fat tissue. Without enough lipoprotein lipase, diabetics may have a high triglyceride level ${ }^{19}$. The diabetics who do not control their sugar level can have a triglyceride level and can cause the pancreatic inflammation ${ }^{20}$. Certain researches reveal that pancreatitis makes diabetes management even more difficult by inducing peripheral insulin resistance ${ }^{21}$.

Studies conducted in china reports that people with T2DM may show increased risk of some type of cancers to develop ${ }^{22}$ and higher BMI can be an important player in the development of cancers specially in females with type 2 Diabetes Mellitus ${ }^{23}$.

The ADA (American diabetic association) and AHA (American heart association) both have acknowledged that diabetes can be considered as coronary heart disease equivalent and patients should be start taking treatment for secondary prevention of coronary heart disease ${ }^{24}$.

Strong evidence suggests lifestyle interventions in people at high risk for diabetes and for people with strong familial disposition of disease furthermore its 
onset can be delayed by keeping good control upon cardio metabolic risk factors like blood sugar, blood pressure, and lipids ${ }^{25}$.

\section{CONCLUSION}

Diabetic patients have the high risk of developing various diseases including CVD. Observance of lipid guidelines is very important for improvement of disease. According to our estimates there is positive correlation of $2 \mathrm{~h}-\mathrm{PG}$ with the lipid profile. As the level of glucose in blood is increasing the lipid profile also tend to increase. There is an important relationship in between $2 \mathrm{~h}-\mathrm{PG}$ and lipid profile. In this study, males had higher levels lipid profile as compared to females. We will further confirm our findings by extending our research in other parts of the Sindh, Pakistan.

\section{Conflict of interest}

The study was conducted without any public/private funding. The authors of this manuscript state that do not have any financial/ethical/literary conflict of interest and nothing to disclose

Informed consent was obtained from all individual participant included in the study.

\section{REFERENCES}

1. Zaccardi F, Webb DR, Yates T, Davies MJ. Pathophysiology of type 1 and type 2 diabetes mellitus: a 90-year perspective. Postgrad Med J 2016; 92(1084):63-9. doi: 10.1136/postgradmedj -2015-133281.

2. Kahn SE, Cooper ME, Del Prato S. Pathophysiology and treatment of type 2 diabetes: perspectives on the past, present, and future. Lancet 2014; 383(9922):1068-83. doi: 10.1016/ S0140-6736(13)62154-6.

3. American Diabetes Association. (2) Classification and diagnosis of diabetes. Diabetes Care 2015; 38(Supplement 1):S8-S16. doi: 10.2337/dc15S005.

4. Mohsen L, Abou-Alam M, El-Dib M, Labib M, Elsada $\mathrm{M}$, Aly $\mathrm{H}$. A prospective study on hyperglycemia and retinopathy of prematurity. J Perinatol 2014; 34(6):453-7. doi: 10.1038/jp.2014.49.

5. Vinik Al, Nevoret ML, Casellini C, Parson $H$. Diabetic neuropathy. Endocrinol Metab Clin North Am 2013; 42(4):747-87. doi:10.1016/ j.ecl.2013.06.001

6. Goyal R, Jialal I. Diabetes Mellitus, Type 2. StatPearls Publishing, Treasure Island(FL); 2018.

7. Asmat U, Abad K, Ismail K. Diabetes mellitus and oxidative stress-A concise review.Saudi Pharm J 2016; 24(5):547-553.

8. Wild S, Roglic G, Green A, Sicree R, King $H$. Global prevalence of diabetes: estimates for the year 2000 and projections for 2030. Diabetes care. $2004 ; 27(5): 1047-53$.

9. Reinehr T. Type 2 diabetes mellitus in children and adolescents. World J Diabetes 2013; 4(6):270 -81. Doi: 10.4239/wjd.v4.i6.270.

10. Kota SK, Meher LK, Jammula S, Kota SK, Modi KD. Genetics of type 2 diabetes mellitus and other specific types of diabetes; its role in treatment modalities. Diabetes \& Metab Syndr 2012; 6(1):54 -8. doi: 10.1016/j.dsx.2012.05.014.

11. Guariguata L, Whiting DR, Hambleton I, Beagley J, Linnenkamp U, Shaw JE. Global estimates of diabetes prevalence for 2013 and projections for 2035. Diabetes Res Clin Pract. 2014; 103(2): 137-49. doi: 10.1016/j.diabres.2013.11.002.

12. Tajima N, Morimoto A. Epidemiology of childhood diabetes mellitus in Japan. Pediatric Endocrinol Rev 2012; 10:44-50.

13. American Diabetes Association. Diagnosis and classification of diabetes mellitus. Diabetes Care. 2014; 37(Suppl 1):S81-S90. doi: 10.2337/dc 14-S081.

14. Tagoe DNA, Amo-Kodieh P. Type 2 diabetes mellitus influences lipid profile of diabetic patients. Annals of Biological Research. 2013;4(6):88-92.

15. Islam MZ, Islam MN, Bhowmik TK, Roy AK, Saha B, Hossain MS, et al. Association of Low Level of High Density Lipoprotein cholesterol with Acute Coronary syndrome. Mymensingh Med J 2018; 27 (3):508-512 .

16. Rohatgi A, Khera A, Berry JD, Givens EG, Ayers $\mathrm{CR}$, Wedin KE, et al. HDL cholesterol efflux capacity and incident cardiovascular events. N Engl J Med. 2014; 371(25):2383-93. doi: 10.1056/ NEJMoa1409065.

17. Hirano T. Pathophysiology of Diabetic Dyslipidemia. J Atheroscler Thromb 2018; 25(9):771-81.

18. Gonzales R, Kutner J. Current Practice Guidelines in Primary Care. $9^{\text {th }}$ ed, McGraw-Hill Professional; 2008.

19. Tani M, Horvath KV, Lamarche $B$, Couture $P$, Burnett JR, Schaerfer EJ, et al. High-density lipoprotein subpopulation profiles in lipoprotein lipase and hepatic lipase deficiency. Artherosclerosis 2016; 253:7-14.

20. Scherer J, Singh VP, Pitchumoni CS, Yadav D. Issues in hypertriglyceridemic pancreatitis-an update. J Clinl Gastroenterol 2014; 48(3):195-203. doi: 10.1097/01.mcg. 0000436438. 60145. 5a

21. Caney SM. Pancreatitis and diabetes in cats. Vet Clin North Am Small Anim Pract 2013; 43(2):30317. doi: 10.1016/j.cvsm.2012.12.001.

22. Hui-Lin $\mathrm{Xu}$, Hong Fang, Wang-Hong $\mathrm{Xu}$, Guo-You Qin, Yu-Jie Yan, Bao-Dong Yao at el,. Cancer incidence in patients with type 2 diabetes mellitus: a population-based cohort study in Shanghai. 
BMC Cancer 2015; 15:852. doi: 10.1186/s12885015-1887-4.

23. Hui-Lin $X U$, Hong Fang, Wang-Hong $X U$, Guo-You Qin, Yu-Jie Yan, Bao-Dong Yao, et al. Body mass index and the risk of mortality among Chinese adults with Type 2 diabetes. Diabetic Med. 2018; 35(11):1562-1570. doi: 10.1111/ dme.13763. .
24. Flegal KM, Carroll MD, Ogden CL, Johnson CL. Prevalence and trends in obesity among US adults, 1999-2000. JAMA 2002; 288(14):1723-7.

25. Haw JS, Narayan KM, Ali MK. Quality improvement in diabetes--successful in achieving better care with hopes for prevention. Ann N Y Acad Sci 2015; 1353:138-51. doi: 10.1111/nyas.12950.

\begin{tabular}{|l|}
\hline AUTHOR AFFILIATION: \\
Latafat Ali Chughtai \\
Assistant Professor, Department of Physiology \\
University of Sindh, Jamshoro-Sindh-Pakistan. \\
Jawaid Ahmed Zai \\
Assistant Professor, Department of Physiology \\
University of Sindh, Jamshoro-Sindh-Pakistan. \\
Zaib u nisa Mughal \\
Assistant Professor, Department of Physiology \\
University of Sindh, Jamshoro-Sindh-Pakistan. \\
Benazir Faheem (Corresponding Author) \\
Student, Department of Physiology \\
University of Sindh, Jamshoro-Sindh-Pakistan. \\
Email: beenafs@hotmail.com
\end{tabular}

